\title{
SISTEMAS DE PISOS PARA A SALA DE ATIVIDADES DE ESCOLA INFANTIL: CRITÉRIOS GERAIS EXIGÍVEIS PARA CONFORTO
}

\section{FLOOR SYSTEMS FOR THE CHILDREN'S SCHOOL ACTIVITIES ROOM: GENERAL REQUIREMENTS FOR COMFORT}

\author{
(Nébora Lazzarotto Modler) \\ (Luís Eduardo Azevedo Modler) \\ (1) Universidade Federal da Fronteira Sul (UFFS) \\ e-mail:nebora.modler@uffs.edu.br \\ (2) Universidade Federal da Fronteira Sul(UFFS) \\ e-mail: luis.modler@uffs.edu.br
}

Arquitetura escolar infantil, Pisos, Conforto

O piso da sala de atividades da escola de educação infantil contribui para o processo de desenvolvimento da criança, através de experiências sensoriais e motoras. Este trabalho investiga a adequação de diferentes pisos para atender ao uso escolar considerando as necessidades de conforto ambiental em termos de segurança e bem-estar.

\section{Children's school architecture, Floors, Comfort}

The floor of the children's school activities room contributes to the children's development process, as it enables sensory and motor experiences. This study researches which floors are best suited to attend school use considering environmental comfort needs in terms of safety and well-being.

\section{Introdução}

O documento Parâmetros Nacionais de InfraEstrutura Para as Instituições de Educação Infantil [BRASIL 2006:21] reconhece a criança como "sujeito do processo educacional e como principal usuária do ambiente educacional". Conforme Campos de Carvalho [1994 apud Horn 2007: 76], "o espaço é parte integrante da ação pedagógica, e não apenas um pano de fundo".O piso da sala de atividades assume papel relevante visto que abriga o sentar, o engatinhar e os primeiros passos dos pequenos, bem como proporciona experiências sensoriais devido ao contato corporal com a superfície. Tais experiências proporcionam estímulos devido à alta capacidade multissensorial que as crianças pequenas são dotadas [RINALDI, 2013:14]. Contudo, para que possa ser explorado pedagogicamente é necessário que o piso seja confortável e seguro. A partir desta abordagem, o este artigo objetiva investigar quais sistemas de pisos são mais adequados para atender ao uso em salas de atividades infantis localizadas no sul do Brasil, considerando o conforto e as exigências técnicas. O trabalho é organizado em duas etapas (1) análise qualitativa de pisos em madeira, cerâmico, linóleo e vinílico, (2) análise quanto as propriedades de efusividade térmica, transmissão térmica e atraso térmico segundo os procedimentos 


\section{$16^{\circ}$ \\ ERGODESIGN USIHC CINAHPA}

da NBR 15.220-3 [ABNT 2005].

\section{Critérios gerais exigíveis}

Quanto ao conforto acústico, o piso dever ter como acabamento um material com propriedades absorvedoras do som a fim de não promover reflexões que tornam o ambiente perturbador, tanto em termos de ruído aéreo como de impacto [SOUZA et al, 2012; NBR 12.179, 1992]. Com relação ao conforto lumínico, os aspectos visuais de cor e brilho também devem ser considerados, a fim de se obter um adequado índice de reflexão luminosa. Segundo Paes [2008:133], o uso de cores intermediárias, como o cinza, contempla tais requisitos. No que se refere às questões de conforto funcional e acessibilidade, o piso deve ser antiderrapante [BRASIL 2006: 33] e resiliente para reduzir o impacto das quedas [GSA, 2003:9]. Também precisa ser livre de saliências para evitar tropeços, risco este gerado pelos tapetes de tecido e emborrachados comumente utilizados. No que tange à qualidade do ar, a prescrição deve atentar para as superfícies de acabamento que não emanam gases tóxicos como os identificados por Compostos Orgânicos Voláteis (COV). Os COV são liberados para o ar durante o processo de volatização do solvente presentes em alguns tipos de tintas e vernizes. Segundo Schimd [2005:154], os COV estão relacionados a efeitos irritantes das vias respiratórias e, em longo prazo, possibilidade de desenvolvimento de câncer. A manutenção da saúde dos ocupantes das salas também depende das condições de higiene dos pisos. Os pisos devem ser laváveis, de fácil manutenção e com menor número de juntas possíveis às quais contribuem para favorecer o acúmulo de poeira e umidade [BRASIL 2006:33]. Conforme Paes [2008:131], os acabamentos de pisos devem ser duráveis para suportar o uso intenso sem exigir reposições frequentes. A autora também salienta que se deve antever os produtos de limpeza que serão necessários para a manutenção durante a vida útil do piso, visto que existem produtos domésticos que liberam COV. Em termos de conforto térmico, o piso deve resultar num baixo índice de transmitância e eficiente inércia térmica que está relacionada a um alto atraso térmico, para assim minimizar as perdas de calor do ambiente interno $16^{\circ}$ Ergodesign - Congresso Internacional de Ergonomia e Usabilidade de Interfaces Humano Tecnológica: Produto, Informações Ambientes Construídos e Transporte

$16^{\circ}$ USIHC - Congresso Internacional de Ergonomia e Usabilidade de Interfaces Humano Computador

CINAHPA | 2017 - Congresso Internacional de Ambientes Hipermídia para Aprendizagem.

para o solo. Também a prescrição dever selecionar material de acabamento superficial com baixa efusividade térmica a fim de evitar a sensação de frio oriundo do contato com o piso [LAMBERTS et al 2011; EFFTING, 2008].

\section{Caracterização dos sistemas de pisos}

A seguir é realizada a caracterização dos pisos analisados. Para todos os tipos a base é constituída por laje de concreto com contrapiso zero, e, para o piso cerâmico é considerada camada de contrapiso.

\subsection{Tacos de Madeira}

O piso de tacos é constituído por madeira maciça com densidade própria para assoalho. As dimensões são $7 \mathrm{~cm}$ largura, $2 \mathrm{~cm}$ espessura e $21 \mathrm{~cm}$ comprimento. Os tacos são encaixados e colados, e o acabamento final é dado com lixamento e verniz.

\subsection{Cerâmico}

O piso cerâmico considerado é do tipo grés com PEI 4 em função de haver possibilidade de presença de areia nos calçados, oriundo das áreas de recreação aberta da escola. A superfície de acabamento é do tipo esmaltada acetinada e não lisa, para facilitar a limpeza sem ser escorregadia.

\subsection{Linóleo}

O revestimento linóleo é, predominantemente, constituído por matérias-primas naturais renováveis e está disponível no mercado na forma de mantas flexíveis e placas. Neste trabalho é analisado o piso em mantas com espessura de $2,5 \mathrm{~mm}$ por $2 \mathrm{~m}$ de largura. Não é realizada aplicação de acabamento, visto que o linóleo contém cera ou resina em sua constituição, o que confere proteção à superfície. A instalação é realizada a partir da colagem das mantas sobre a base de concreto.

\subsection{Vinílico}

O revestimento vinílico é constituído em sua totalidade por policloreto de vinila (PVC). A instalação é realizada de maneira análoga ás mantas de linóleo. Não é necessário acabamento de
Realização:

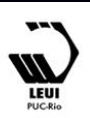




\section{$16^{\circ}$ \\ ERGODESIGN USIHC CINAHPA}

proteção após a instalação, pois o revestimento vinílico conta com resina poliuretânica.

\section{Metodologia}

Os procedimentos de análise foram organizados em duas etapas: na primeira, é realizada análise qualitativa de sistemas de pisos em madeira, cerâmico, linóleo e vinílico, com base nos critérios de conforto acústico, qualidade do ar, segurança e higiene apresentados no item 2. Na segunda etapa, os sistemas de pisos são analisados quanto ao desempenho térmico, especificamente quanto às suas propriedades de efusividade térmica, transmissão térmica e atraso térmico, segundo os procedimentos definidos na NBR 15.220-3. A verificação quanto ao conforto lumínico evidencia que todos os pisos predefinidos para a análise têm cores intermediárias, capazes de promover a reflexão luminosa e aproveitamento da iluminação, desta forma este critério é considerado como atendido. Também se entende que o critério técnica de instalação e manutenção é atendido satisfatoriamente pelos sistemas predefinidos.

\section{Análise qualitativa de sistemas de pisos}

\subsection{Piso em tacos de madeira}

(1) Conforto acústico: o piso em madeira, segundo a NBR 12.179 [ABNT, 1992], apresenta absorção acústica da ordem de 0,4 a 0,10 , considerando a faixa na qual predomina a voz humana, que se estendem de $250 \mathrm{~Hz}$ a $2000 \mathrm{~Hz}$. (Tabela 1). Logo, considera-se que o critério acústico é atendido pelo piso em tacos de madeira.

Tabela 1- Coeficientes de absorção acústica madeira

\begin{tabular}{l|l|l|l|l}
\hline & \multicolumn{4}{|c}{ Frequências } \\
\hline & 250 & 500 & 1000 & 2000 \\
\hline Tacos madeira & 0,04 & 0,06 & 0,12 & 0,10 \\
\hline
\end{tabular}

Adaptada da NBR 12. 179, pág. 5 [ABNT, 1992]

(2) Qualidade do ar: o piso possui superfície de acabamento em verniz poliuretânico, o qual tem base solvente, que, por sua vez, libera Compostos Orgânicos Voláteis (COV), dentre estes os hidrocarbonetos. A liberação dos hidrocarbonetos ocorre de forma mais intensa durante o processo de secagem do verniz, mas continua após este $16^{\circ}$ Ergodesign - Congresso Internacional de Ergonomia e Usabilidade de Interfaces Humano Tecnológica: Produto, Informações Ambientes Construídos e Transporte

$16^{\circ}$ USIHC - Congresso Internacional de Ergonomia e Usabilidade de Interfaces Humano Computador

CINAHPA | 2017 - Congresso Internacional de Ambientes Hipermídia para Aprendizagem. período, o que prejudica a qualidade do ar da sala, principalmente se o ambiente for mantido sem a adequada renovaçãodo ar. Assim, considera-se que o sistema atende parcialmente o critério qualidade do ar, visto que a emanação de COV da superfície de acabamento decresce ao longo do tempo. (3) Segurança: o piso em tacos apresenta características satisfatórias, visto que não oferece risco de saliências. Também é resilente para amortecer quedas e antiderrapante sem apresentar rugosidade. Logo, o critério segurança é atendido. (4) Higiene: o piso é lavável, contudo, quando a superfície de verniz de acabamento estiver comprometida ocorre acúmulo de poeira e umidade nas juntas. Dessa forma, considera-se este critério parcialmente atendido.

\subsection{Piso cerâmico}

(1) Quanto ao conforto acústico: a norma de referência não apresenta o índice de absorção de cerâmicas, contudo, por apresentar superfície dura e lisa, pode ser comparada com o reboco liso com coeficiente de absorção acústica de 0,02 a 0,03 (Tabela 2). Também, por apresentar acabamento duro, transmite o ruído de impacto para as paredes da sala. Assim, o critério acústico não é atendido.

Tabela 2- Coef. de absorção acústica piso cerâmico

\begin{tabular}{l|c|c|c|c}
\hline & \multicolumn{4}{|c}{ Frequências (Hz) } \\
\hline $\begin{array}{l}\text { Cerâmica ou } \\
\text { reboco liso }\end{array}$ & 250 & 500 & 1000 & 2000 \\
\hline
\end{tabular}

Adaptada da NBR 12. 179, pág. 5 [ABNT, 1992]

(2) Qualidade do ar: a cerâmica não emana poluentes, sendo o critério atendido. (3) Segurança: o piso cerâmico é livre de saliências, mas oferece risco por sua dureza, também, em dias com umidade do ar alta, comuns na região em estudo, a condensação que se forma sobre a superfície pode causar escorregamentos. Assim, o critério segurança não é atendido. (4) Higiene: o revestimento cerâmico é lavável, portanto cumpre o critério higiene. Sendo que deve ser utilizado o tipo de rejunte que evite a propagação de fungos.

\subsection{Piso linóleo}

(1) Conforto acústico: segundo a NBR 12.179
Realização:

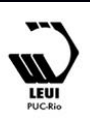




\section{$16^{\circ}$ \\ ERGODESIGN USIHC CINAHPA}

$16^{\circ}$ Ergodesign - Congresso Internacional de Ergonomia e Usabilidade de Interfaces Humano Tecnológica: Produto, Informações Ambientes Construídos e Transporte

$16^{\circ}$ USIHC - Congresso Internacional de Ergonomia e Usabilidade de Interfaces Humano Computador

CINAHPA | 2017 - Congresso Internacional de Ambientes Hipermídia para Aprendizagem.
[ABNT, 1992], o revestimento linóleo apresenta características de absorção da ordem de 0,03 a 0,04 (Tabela 3). Por contar com constituição amortecedora, o linóleo absorve ruído de impacto, o que garante $\mathrm{o}$ atendimento do critério acústico.

Tabela 3- Coef. de absorção acústica piso linóleo

\begin{tabular}{c|c|c|c|c}
\hline & \multicolumn{4}{|c}{ Frequências (Hz) } \\
\hline & 250 & 500 & 1000 & 2000 \\
\hline Piso linóleo & - & 0,03 & - & 0,04 \\
\hline
\end{tabular}

(2) Qualidade do ar: o piso linóleo não emana poluentes, pois conta com composição a base de matérias-primas naturais, sendo assim, atende a exigência de qualidade do ar. (3) Segurança: o piso linóleo é considerado satisfatório, uma vez que é resiliente, livre de saliências e antiderrapante, sem ser rugoso. (4) Higiene: o linóleo é lavável, bem como não acumula agentes alergênicos e ácaros, pois as juntas são praticamente inexistentes, portanto cumpre a exigência de higiene.

\subsection{Piso vinílico}

(1) Conforto acústico: a norma de referência não apresenta o índice de absorção acústica de revestimentos vinílicos, contudo, por apresentar superfície amortecedora, pode ser comparada com tapetes de borracha cujo coeficiente de absorção é de 0,04 a 0,12 (Tabela 4). Por contar com constituição amortecedora é capaz de absorver o ruído de impacto, o que garante o atendimento ao critério acústico.

Tabela 4- Coef. de absorção acústica em pisos de borracha/vinílico

\begin{tabular}{c|c|c|c|c}
\hline & \multicolumn{4}{|c}{ Frequências (Hz) } \\
\hline & 250 & 500 & 1000 & 2000 \\
\hline Piso linóleo & 0,04 & 0,08 & 0,12 & 0,03 \\
\hline \multicolumn{4}{c}{ Adaptada da NBR 12. 179, pág. 6 [ABNT, 1992] }
\end{tabular}

(2) Qualidade do ar: a superfície vinílica emana $\mathrm{COV}$, dentre estes o cloreto de vinila, que em ambientes mal ventilados pode vir a apresentar concentrações consideradas críticas para a saúde humana. Também, em situações de incêndio, a queima de PVC produz vapores tóxicos [SCHIMD 2005:155]. Por essas razões o revestimento vinílico não atende ao critério qualidade do ar. (3)
Segurança: o piso vinílico é considerado satisfatório, uma vez que é resiliente, livre de saliências e antiderrapante, sem ser rugoso. (4) Higiene: o piso vinílico apresenta os mesmos atributos de higiene que o linóleo - é lavável, bem como não acumula agentes alergênicos e ácaros.

\subsection{Síntese da análise qualitativa}

Tendo em vista que os sistemas de pisos analisados apresentam características distintas quanto aos aspectos analisados, optou-se por sintetizar tais informações a fim de elucidar os resultados. (Quadro 1).

Quadro 1 - Síntese da análise qualitativa

\begin{tabular}{l|c|c|c|c|c|c}
\hline & $\begin{array}{l}\text { Conforto } \\
\text { lumínico }\end{array}$ & técnica & $\begin{array}{l}\text { Conf. } \\
\text { acústico }\end{array}$ & $\begin{array}{l}\text { qualidade } \\
\text { do ar }\end{array}$ & $\begin{array}{l}\text { seguran } \\
\text { ça }\end{array}$ & higiene \\
\hline M & A & A & A & AP & A & AP \\
\hline C & A & A & NA & A & AP & A \\
\hline L & A & A & A & A & A & A \\
\hline V & A & A & A & NA & A & A \\
\hline
\end{tabular}

O piso vinílico, por não atender aos critérios de qualidade do ar, bem como por apresentar risco de intoxicação em situações de incêndio, é, neste estudo, considerado inviável para salas de atividades. Portanto, este sistema não será considerado na análise de desempenho térmico. A cerâmica, apesar de não atender ao critério acústico, será considerada na próxima etapa da análise, pois se entende que as paredes e o mobiliário também contribuem com a absorção, o que pode compensar a reflexão do piso.

\section{Análise de desempenho térmico}

O objetivo da análise de desempenho térmico é descobrir o quanto o sistema de piso contribui para a condição de conforto térmico das crianças. Para tanto, são analisadas as propriedades dos materiais transmitância térmica e atraso térmico, as quais interferem no desempenho. Também é considerada a percepção de conforto oriunda do contato direto com a superfície, a qual está relacionada com a efusividade térmica e a resistência de contato que é influenciada pela rugosidade da superfície dos pisos [EFFTING, 2008:40]. Os materiais de alta efusividade térmica parecem mais frios ao contato da pele com a superfície, já os de baixa efusividade 


\section{$16^{\circ}$ \\ ERGODESIGN USIHC CINAHPA}

transmitem a sensação de maior temperatura. Também a sensação de calor ou frio no contato com o piso liso é maior do que com o rugoso devido a maior área de contato, que equivale à área de transferência de calor, entre a pele e a superfície lisa. O cálculo do desempenho dos sistemas de pisos é efetuado conforme os procedimentos prescritos na NBR 15.220-3[ABNT, 2005b]. A análise do conforto relacionado ao contato, que é representado pela efusividade térmica, é realizado a partir da comparação dos valores de condutivilidade e densidade térmica, bem como quanto as características de acabamento da superfície [EFFTING, 2008:40].

\subsection{Piso em tacos de madeira}

O piso em tacos de madeira, na comparação com os demais pisos analisados nessa etapa, apresenta o melhor desempenho, sendo a transmitância térmica igual a $2,73 \mathrm{~W} /\left(\mathrm{m}^{2} . \mathrm{K}\right)$ e o atraso térmico equivalente a 4,34h. A efusividade também é satisfatória, apesar de a superfície de acabamento ser lisa, uma vez que os valores de condutividade $\left(0,23 \mathrm{~W} /(\mathrm{m} . \mathrm{K})\right.$ e densidade $\left(750 \mathrm{~W} / \mathrm{m}^{2}\right)$ são considerados baixos (Tabelas 5 e 6 ).

Tabela 5-Análise/síntese qualitativa piso de madeira

\begin{tabular}{c|c|c|c|c|c|c}
\hline & $\begin{array}{c}\lambda \\
W /(m . K)\end{array}$ & $\begin{array}{c}c \\
J /(k g . K)\end{array}$ & $\begin{array}{c}\rho \\
W / m^{2}\end{array}$ & $\begin{array}{c}e \\
m\end{array}$ & $\begin{array}{c}R \\
\left(m^{2} . K\right) / W\end{array}$ & $\begin{array}{c}C \\
J / K\end{array}$ \\
\hline madeira & 0,23 & 1,34 & 750 & 0,02 & 0,086 & 20,1 \\
\hline concreto & 1,75 & 1 & 2200 & 0,12 & 0,068 & 264 \\
\hline
\end{tabular}

Tabela 6 - Propriedade térmicas do piso de madeira

\begin{tabular}{|c|c|c|c|c|}
\hline $\begin{array}{l}C T \\
J / K \\
\end{array}$ & $\begin{array}{c}R t \\
(m 2 . K) / W \\
\end{array}$ & $\begin{array}{c}R T \\
(m 2 . K) / W \\
\end{array}$ & $\begin{array}{c}h \\
\text { horas } \\
\end{array}$ & $\begin{array}{c}U \\
W /\left(m^{2} \cdot k\right) \\
\end{array}$ \\
\hline 284,10 & 0,15 & 0,36 & 4,34 & 2,73 \\
\hline
\end{tabular}

Legenda ${ }^{2}$ : CT capacidade ter.; Rt resistência ter. superfície a superfície; RT resistência tot.; h atraso tér.; U transmitância ter.

\subsection{Piso cerâmico}

O piso cerâmico apresenta transmitância térmica de $3,38 \mathrm{~W} /\left(\mathrm{m}^{2} . \mathrm{K}\right)$ e atraso térmico de $3,22 \mathrm{~h}$. A efusividade não é satisfatória, pois os valores de

\footnotetext{
${ }^{1}$ Cálculos conforme NBR15.220-3[2005] e MORISHITA et al [2011]; valores de Resistência e Capacidade térmica da camada calculados segundo a NBR15.220-3(2005)

2 Índices calculados segundo a NBR15.220-3[2005]
}

$16^{\circ}$ Ergodesign - Congresso Internacional de Ergonomia e Usabilidade de Interfaces Humano Tecnológica: Produto, Informações Ambientes Construídos e Transporte

$16^{\circ}$ USIHC - Congresso Internacional de Ergonomia e Usabilidade de Interfaces Humano Computador

CINAHPA | 2017 - Congresso Internacional de Ambientes Hipermídia para Aprendizagem.

condutividade $(1,05 \mathrm{~W} /(\mathrm{m} . \mathrm{K})$ e densidade $\left(2000 \mathrm{~W} / \mathrm{m}^{2}\right)$ são significativamente superiores do que os demais pisos analisados (Tabelas 7 e 8 ).

Tabela 7 - Síntese da análise qualitativa piso cerâmico

\begin{tabular}{c|c|c|c|c|c|c}
\hline & $\begin{array}{c}\lambda \\
W /(m \cdot K)\end{array}$ & $\begin{array}{c}c \\
J /(k g . K)\end{array}$ & $\begin{array}{c}\rho \\
W / m^{2}\end{array}$ & $\begin{array}{c}e \\
m\end{array}$ & $\begin{array}{c}R \\
\left(m^{2} \cdot K\right) / W\end{array}$ & $\begin{array}{c}C \\
J / K\end{array}$ \\
\hline cerâmica & 1,05 & 0,92 & 2000 & 0,01 & 0,009 & 18,4 \\
\hline concreto & 1,75 & 1 & 2200 & 0,12 & 0,068 & 264 \\
\hline argamassa & 1,15 & 1 & 2000 & 0,008 & 0,006 & 16 \\
\hline
\end{tabular}

Legenda $^{1}: \lambda$ condutividade; $c$ calor específico; $\rho$ densidade de massa aparente; e espessura; $\mathrm{R}$ resistência camada; $\mathrm{C}$ Capacidade ter. camada

Tabela 8 - Propriedade térmicas do piso cerâmico

\begin{tabular}{c|c|c|c|c}
\hline $\begin{array}{c}C T \\
J / K\end{array}$ & $\begin{array}{c}R t \\
(m 2 . K) / W\end{array}$ & $\begin{array}{c}R T \\
(m 2 . K) / W\end{array}$ & $\begin{array}{c}h \\
\text { horas }\end{array}$ & $\begin{array}{c}U \\
W /\left(m^{2} \cdot k\right)\end{array}$ \\
\hline 298,4 & 0,085 & 0,295 & 3,22 & 3,38 \\
\hline \multicolumn{2}{c}{ Legenda': CT capacidade ter.; Rt resistência ter. superfície a } \\
superfície; RT resistência tot.; h atraso tér.;U transmitância ter.
\end{tabular}

\subsection{Piso linóleo}

O piso em revestimento linóleo apresenta desempenho semelhante ao sistema cerâmico em relação aos valores de transmitância térmica $(3,41$ $\mathrm{W} /\left(\mathrm{m}^{2} . \mathrm{K}\right)$ e atraso térmico $(3,09 \mathrm{~h})$. Contudo, a análise quanto á efusividade aponta este sistema como mais eficiente, em função do valores de condutividade $(0,17 \mathrm{~W} /(\mathrm{m} . \mathrm{K})$ e densidade $(1200$ $\mathrm{W} / \mathrm{m}^{2}$ ), os quais são inferiores ao piso cerâmico (Tabelas 9 e 10).

Tabela 9 - Síntese da análise qualitativa piso linóleo

\begin{tabular}{c|c|c|c|c|c|c}
\hline & $\lambda$ & $c$ & $\rho$ & $e$ & $R$ & $C$ \\
& $W /(m \cdot K)$ & $J /(k g . K)$ & $W / m^{2}$ & $m$ & $\left(m^{2} \cdot K\right) / W$ & $J / K$ \\
\hline linóleo & 0,17 & 1,4 & 1200 & 0,0025 & 0,014 & 4,2 \\
\hline concreto & 1,75 & 0,12 & 1 & 2200 & 0,068 & 264 \\
\hline
\end{tabular}

Legenda $^{1}: \lambda$ condutividade; $c$ calor específico; $\rho$ densidade de massa aparente; e espessura; $\mathrm{R}$ resistência camada; $\mathrm{C}$ Capacidade ter. camada

Tabela 10 - Propriedade térmicas do piso linóleo

\begin{tabular}{c|c|c|c|c}
\hline $\begin{array}{c}C T \\
J / K\end{array}$ & $\begin{array}{c}R t \\
(m 2 . K) / W\end{array}$ & $\begin{array}{c}R T \\
(m 2 . K) / W\end{array}$ & $\begin{array}{c}h \\
\text { horas }\end{array}$ & $\begin{array}{c}U \\
W /\left(m^{2} \cdot k\right)\end{array}$ \\
\hline 268,2 & 0,08 & 0,29 & 3,09 & 3,41 \\
\hline \multicolumn{4}{r}{ Legenda ${ }^{2}$ CT capacidade ter.; Rt resistência ter. superfície a }
\end{tabular}

superfície; RT resistência tot.; h atraso tér.; U transmitância ter.

\section{Considerações Finais}

O trabalho apresenta estudo de critérios exigíveis a pisos para salas de atividades de escolas infantis localizadas no sul do Brasil, com o objetivo de investigar quais sistemas de pisos são mais adequados para atender às necessidades de conforto e segurança das crianças. $\mathrm{O}$ estudo foi
Realização:

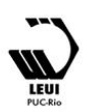




\section{$16^{\circ}$ \\ ERGODESIGN USIHC CINAHPA}

$16^{\circ}$ Ergodesign - Congresso Internacional de Ergonomia e Usabilidade de Interfaces Humano Tecnológica: Produto, Informações Ambientes Construídos e Transporte

$16^{\circ}$ USIHC - Congresso Internacional de Ergonomia e Usabilidade de Interfaces Humano Computador

CINAHPA | 2017 - Congresso Internacional de Ambientes Hipermídia para Aprendizagem. dividido em etapas: (1) análise qualitativa de pisos em madeira, cerâmica, linóleo e vinílico, (2) análise quanto ao desempenho e conforto térmico. A análise qualitativa, a qual considerou os critérios de conforto lumínico, técnica e manutenção, conforto acústico, qualidade do ar, segurança e higiene, apontou que os pisos atendem integralmente ou parcialmente os critérios elencados, sendo exceções: (1) o piso cerâmico não atende à exigência acústica, em função de promover reflexão sonora, também a cerâmica, por contar com superfície dura, não amortece as possíveis quedas das crianças; (2) o piso vinílico não atende à exigência de qualidade do ar, uma vez que emana COV prejudicial a saúde, também, em incêndio, libera vapores tóxicos, o que torna inviável a sua utilização em salas infantis. A análise quanto ao conforto térmico aponta o piso de madeira como o mais adequado em função de apresentar valores de efusividade e transmistância térmica reduzidos e atraso térmico elevado. Também se constatou que o linóleo é um piso com atributos próprios para o uso no ambiente considerado, em função de sua resiliência e higiene. Indica-se inserir sob o piso uma camada de material isolante térmico, a fim de reduzir a transmitância e aumentar o atraso térmico. $\mathrm{O}$ estudo revelou que a cerâmica não atende ao critério de conforto térmico devido à alta efusividade, o que faz com que haja sensação de frio quando ocorre o contato com a superfície. A utilização deste material, só seria possível se fosse associada a um sistema de calefação de piso. A experiência permite concluir que a prescrição do sistema de piso próprio para salas de atividades deve considerar, de forma sistêmica, todos os critérios atuantes na condição de bem-estar e segurança, de outra forma, aspectos relevantes podem ser negligenciados.

\section{BIBLIOGRAFIA}

ABNT a. NBR 15220-1: Desempenho térmico de edificações Parte 1: Definições, símbolos e unidades . Rio de Janeiro: ABNT, 2005.

ABNT b. NBR 15220-2: Desempenho térmico de edificações Parte 2. Rio de Janeiro: ABNT, 2005.
BRASIL. Parâmetros básicos de infra-estrutura para instituições de educação infantil. Brasília, 2006.http://portal.mec.gov.br/seb/arquivos/pdf/Edu cinf/miolo_infraestr.pdf. Acesso em 22 dez. 2015.

EFFTING, C. Desenvolvimento de revestimentos cerâmicos confortáveis termicamente.

2008.141f. Doutorado.UFSC. Florianópolis/SC.

GSA- General Services Administration. Public

Buildings Service Office Of Child Care. 2003.

New York, EUA.

http://www.gsa.gov/portal/category/21987. Acesso em 20 nov. 2016.

HORN, M.G. S. Sabores, cores, sons, aromas - A organização dos espaços na educação infantil. Porto Alegre: Artmed, 2007.

ISO/FDIS 10456. Building materials and products Hygrothermal properties. Geneve, Switzerland, 2007.

LAMBERTS, R.; XAVIER, A. A.; GOULART, S.; VECCHI, R. D. Conforto e stress térmico. Labeee. UFSC: Florianópolis/SC, 2011. http://www.labeee.ufsc.br.

MORISHITA, C.; SORGATO, M. J.; VERSAGE, R.; TRIANA, M. A.; MARINOSKI, D. L.; LAMBERTS, R. Catálogo de propriedades térmicas de paredes e coberturas. UFSC: Florianópolis/SC, 2011.

PAES, R. F. de S. Materiais de Construção e Acabamento para Escolas Públicas na Cidade do Rio de Janeiro Uma Reflexão sob Critérios de Sustentabilidade. PROARQ/UFRJ. RJ: 2008

RINALDI, C. O ambiente da infância. In: CEPPI, G.; ZINI, M. Porto Alegre: Penso, 2013.

SCHMID, A.L. A idéia de conforto: reflexões sobre o ambiente construído. Curitiba: Pacto Ambiental, 2005

SOUZA, A.B. Bê-a-bá da acústica arquitetônica. São Carlos: EdUFSCar, 2012.

\section{Agradecimentos}

Os autores agradecem ao CNPq e à CAPES, pelo apoio recebido. 